Research paper

\title{
Urofecal steroid profiles of captive Blue-fronted parrots (Amazona aestiva) with different reproductive outcomes
}

\author{
Ricardo J.G. Pereira ${ }^{a, 1, *}$, Mauricio D. Christofoletti ${ }^{\mathrm{b}, 1}$, Marcel H. Blank ${ }^{\text {a }}$, José Mauricio B. Duarte ${ }^{\mathrm{c}}$ \\ ${ }^{a}$ Grupo de Estudos para Multiplicação de Aves (GEMA), Departamento de Reprodução Animal, Faculdade de Medicina Veterinária e Zootecnia, Universidade de São Paulo, \\ CEP 05508-900 São Paulo, SP, Brazil \\ ${ }^{\mathrm{b}}$ Programa de Pós-graduação em Medicina Veterinária, Faculdade de Ciências Agrárias e Veterinárias, Universidade Estadual Paulista, CEP 14884-900 Jaboticabal, SP, Brazil \\ ${ }^{\mathrm{C}}$ Núcleo de Pesquisa e Conservação de Cervídeos (NUPECCE), Departamento de Zootecnia, Faculdade de Ciências Agrárias e Veterinárias, Universidade Estadual Paulista, \\ CEP 14884-900 Jaboticabal, SP, Brazil
}

\section{A R T I C L E I N F O}

\section{Article history:}

Received 18 August 2017

Revised 6 February 2018

Accepted 6 February 2018

Available online 7 February 2018

\section{Keywords:}

Birds

Psittacines

Noninvasive endocrinology

Sexual activity

Androgens

Progestagens

\begin{abstract}
A B S T R A C T
Despite Psitaciformes (parrots) being the third largest nonpasserine order (398 species), it currently ranks second in number of threatened species (28\%) according to the Internatinal Union for Conservation of Nature (IUCN) criteria. Since most of the literature concerning reproductive endocrinology in avian species derives from domestic and song birds, it is puzzling that advances in reproductive science for the Psitaciformes order lags far behind, in spite of the growing threats against them. In order to expand our knowledge of Neotropical parrots (Psittacidae), we examined annual changes in urofecal sex steroid metabolites of Blue-fronted amazon pairs (Amazona aestiva) exhibiting successful (nestlings) and unsuccessful breeding (infertile or no eggs). Urofecal samples were collected over a year from eight breeding pairs housed under the same environmental and management conditions. Fecal androgen and progestagen concentrations were determined in males and females, respectively, by enzyme immunoassays previously validated for this species. All eggs were registered between late winter and mid-spring, and egglaying intervals varied between females (range: 1-8 days; average $3.60 \pm 0.51$ days). Similar profiles of urofecal progestagens were observed in reproductively successful females and females producing infertile eggs, with progestagen peaks preceding egg laying events (1.77 \pm 0.50 days). In contrast, non-laying females had no rises in progestagens during the year. Successful and unsuccessful males did not displayed distinct annual patterns of androgen production, and apart from the peaks during the breeding season, more than half of the individuals intriguingly presented significant increases from late summer to early autumn, a period without reproductive activity. Finally, we noticed that samples with progestagen levels exceeding $40 \mathrm{ng} / \mathrm{g}$ had very high probability ( $>97.5 \%$ ) to be from females in pre-laying or laying phases, suggesting a feasible application of this characteristic to noninvasively discriminate the reproductive status in amazon females with an accuracy and sensitivity of $94.55 \%$ and $58.13 \%$, respectively. Our findings confirmed that urofecal progestagens and androgens are good indicators of the gonadal condition in Blue-fronted amazons, but there is still much to be done for their extensive use in artificial insemination or selection of the most suitable breeding birds for the season.
\end{abstract}

(c) 2018 Elsevier Inc. All rights reserved.

\section{Introduction}

Psittaciformes is one of the most popular orders among pet owners not just for its colorful appearance and charismatic behavior, but also because of its high levels of intelligence and aptitude to imitate a wide range of sounds including the human voice

* Corresponding author at: Departamento de Reprodução Animal, Faculdade de Medicina Veterinária e Zootecnia da Universidade de São Paulo, Av. Prof. Dr. Orlando Marques de Paiva, 87, CEP 05508-900 São Paulo, SP, Brazil.

E-mail address: ricpereira@usp.br (R.J.G. Pereira).

1 These authors equally contributed to this work.
(Olah et al., 2016). Unfortunately, such attributes led to a huge demand for these birds in the pet market. Today psittaciformes represents $20 \%$ of bird species traded globally, second only to Passeriformes (song birds) which represents $70 \%$ of wild birds commercialized worldwide (FAO, 2011). One example of this popularity is depicted by Weston and Memon (2009), who estimated that $75 \%$ of the 11.2 million pet birds in US households were psittacines. As a consequence, international trade contributed to the decline of several parrot populations to the point of having 111 of the 398 known species listed as threatened. Remarkably, recent assessments indicate that $56 \%$ of all psittacine species are still 
experiencing declining numbers worldwide (IUCN, 2014; Olah et al., 2016). This adverse scenario is not different in Brazil, where in spite of exhibiting the greatest diversity of the Psittacidae family (86 species), currently 23 are threatened, one species is presumed extinct, and one species is extinct in the wild (Piacentini et al., 2015; BirdLife International, 2017).

These numbers emphasize the importance of captive breeding to promote either sustainability of global trade of parrots or their conservation. However, large-scale production of psittacines to satisfy pet market demand is restricted to a few species (mostly budgerigars, cockatiels, lovebirds and small conures; Engebretson, 2006), and even for them very little information exists on reproductive endocrinology (Myers et al., 1989; Lee et al., 1999; Costantini et al., 2009; Lovas et al., 2010; Hahn et al., 2011). This lack of endocrinological data for Neotropical parrots hinders future research involving manipulation of reproductive cycles (through artificial lighting or hormone treatments) or adjustments to existing biotechnologies (e.g., artificial insemination). To aid in filling this gap, we sought to use the Blue-fronted amazon (Amazona aestiva) as a model for the genus Amazona (comprising 34 species). This species is assigned to the IUCN Least Concern category (Birdlife International, 2016), has a sizable population in Brazilian zoos and private breeders, and breeds fairly well under appropriate conditions. These parrots are monogamous, seasonal breeders (July-November) and usually produce 2-4 eggs clutch per year that they incubated for about 24-29 days (Sick, 2001; Seixas et al., 2002; Seixas, 2007). Hence, the aims of this study were (1) to examine annual fluctuations of urofecal androgen and progestagen metabolites in male and female Bluefronted amazons, respectively, and (2) to define whether or not measurements of sex steroid metabolites can be used to determine reproductive status in potential breeders. In male birds, testosterone regulates the development of sexual male characteristics, activation of sexual behavior (e.g., courtship and copulation) and sperm production (Deviche et al., 2011; Riters and Alger, 2011). Progesterone is assumed to be the main steroid in female birds involved with ovulation and egg laying, while data shows this hormone to be related to the transition from courtship to incubation behavior (Johnson, 2011; Riters and Alger, 2011).

\section{Material and methods}

\subsection{Animals}

This research was conducted at Brisa commercial breeder located in São Paulo State, South Brazil $\left(21^{\circ} 16^{\prime} 46^{\prime \prime}\right.$ S, $48^{\circ} 13^{\prime} 43^{\prime \prime} \mathrm{W}$; Licenses IBAMA CTF: 263703, AM: 00024/2008-SP and SMA AM: 118748/2015). Eight pairs of Blue-fronted amazon (Amazona aestiva) were kept in suspended breeding aviaries $(1 \mathrm{~m}$ high $\times 1 \mathrm{~m}$ wide $\times 2 \mathrm{~m}$ deep), half-roofed, equipped with external vertical wooden nest boxes ( $45 \mathrm{~cm}$ high $\times 20 \mathrm{~cm}$ wide $\times 20 \mathrm{~cm}$ deep). Adult males and females ( $>5$ years old) were obtained from rescue centers (i.e. seized from illegal parrot traders) and, after a full health check; pairs were formed two months prior to the onset of the study. Once formed, pairs were visually isolated from other pairs. Water and food (extruded pellets manufactured by the breeder) were provided ad libitum through automatic feeders and waterers. Additionally, seasonal fruits (e.g., banana, papaya, mango, guava, grapes, etc.) were provided as behavioral enrichment. Parrots were disturbed as little as possible during the whole monitoring period. All laid eggs were incubated naturally, and unhatched eggs were only withdrawn after females abandoned them. Chicks were removed from the parents for hand feeding at 20 days of age. Experimental procedures for this study comply with the current regulations establish by the Institutional Animal
Care and Use Committee at the Faculdade de Ciências Agrárias e Veterinárias - Universidade Estadual Paulista (Protocol No. 009350/11-CEUA/ FCAVJ).

\subsection{Sample collection, reproductive monitoring and environmental data}

Parrot droppings consist of feces and urine, which are excreted together through the cloaca, and therefore are referred to as urofecal samples. Excreted urofecal samples were collected weekly (on the same day of the week) from each individual from June 2011 to May 2012. Collection of all samples proceeded as follows: beginning at 02:00 PM wire partitions were inserted to separate members of a pair. Next, the aviary floors were lined with clean polyethylene tarpaulins (one per individual bird, to prevent cross-contamination of male and female samples). All fresh urofecal samples voided until 05:00 PM were collected and placed within individually labeled plastic microtubes, and then stored at $-20{ }^{\circ} \mathrm{C}$ until steroid extraction. Sampling frequency was increased to daily whenever egg laying, incubation or parental care was perceived. Parrot pairs were monitored daily through inspections of nests to assess nesting activity (e.g. use of wood pieces deliberately left by investigators inside nests for the parrots to use for making their own bedding material), egg laying and incubation, and chick development. Fertility was confirmed through egg candling following 10 days of incubation. Molt in all individuals was concentrated between January and mid-February. Meteorological data were provided by a weather station at the Faculdade de Ciências Agrárias e Veterinárias - Universidade Estadual Paulista located exactly $7.53 \mathrm{~km}$ away from Brisa commercial breeder $\left(21^{\circ} 14^{\prime} 19^{\prime \prime} \mathrm{S}\right.$, $\left.48^{\circ} 16^{\prime} 55^{\prime \prime} \mathrm{W}\right)$.

\subsection{Steroid extraction and analysis}

Urofecal samples were dried $\left(57^{\circ} \mathrm{C}, 72 \mathrm{hs}\right)$, pulverized, homogenized and extracted as described by Pereira et al. (2010). In general, $0.1 \mathrm{~g}$ of the resulting powder was mixed to $2 \mathrm{~mL}$ of $80 \%$ methanol, while smaller samples $(<0.1 \mathrm{~g})$ were placed in tubes containing proportional amounts of solvent (e.g., $0.03 \mathrm{~g}$ in $0.6 \mathrm{~mL}$ of $80 \%$ methanol). These suspensions were vortexed for $30 \mathrm{~s}$, shaken for $12 \mathrm{~h}(250 \mathrm{rpm})$, and then vortexed again for $30 \mathrm{~s}$ before centrifugation ( $400 \mathrm{~g}$ for $20 \mathrm{~min}$ ). Subsequently, supernatants were transferred into a clean tube and stored at $-20^{\circ} \mathrm{C}$.

Enzyme immunoassay protocols (EIA) were performed following Brown et al. (2004), and antisera for the detection of androgen and progestagen metabolites were supplied by C. Munro (University of California, CA, USA). Cross-reactivities for testosterone antiserum (R156/7) are 100\% with testosterone; 57.3\% with 5adihydrotestosterone; $0.2 \%$ with androstenedione; $0.4 \%$ with androsterone; and $<0.04 \%$ with other tested metabolites (as reported by the manufacturer). Cross-reactivities for progesterone antiserum (CL425) are $100 \%$ with progesterone; $188 \%$ with 4 pregnen-3 $\alpha$-ol-3.20-dione; $172 \%$ with 4 -pregnen-3 $\beta$-ol-20-one; $94 \%$ with $5 \alpha$-pregnan-3 $\beta$-ol-20-one; $64 \%$ with $5 \alpha$-pregnan-3 $\alpha$-ol20 -one; $55 \%$ with $5 \alpha$-pregnan-3,20-dione; $12.5 \%$ with $5 \beta$ pregnan-3 $\beta$-ol-20-one and $\leq 10 \%$ with for all other metabolites tested (Graham et al., 2001). Standard assay validation procedures included assessment of parallelism between serial dilution of Bluefronted amazon urofecal extracts and the respective standard curves, recovery of exogenous analyte, and biological relevance of hormonal data. Recovery tests were performed by combining equal volumes of diluted urofecal extract and known amounts of exogenous hormone and calculating the difference between the expected and observed concentrations of exogenous hormone (androgens: $\mathrm{y}=1.06 \mathrm{x}+1.59, \mathrm{R}^{2}=0.99$; and progestagens: $\mathrm{y}=0.80$ $\mathrm{x}-4.24, \mathrm{R}^{2}=0.98$;). To assess the physiological relevance of 
immunoreactive urofecal androgen metabolites, we challenged two adult Blue-fronted males with buserelin acetate (Conceptal, Intervet, Cotia, Brazil) at a dosage of $8 \mathrm{mg} / \mathrm{kg}$ (Lovas et al., 2010). This resulted in a three-fold increase in androgen levels within 4-8 hs following administration. For urofecal progestagens, physiological and behavioral events from two adult females (i.e. copulation, egg laying and incubation) were employed as part of the biological validation (Christofoletti, 2014). Progestagen peaks were perceived one day before each egg laying event for both females, and no further increases observed throughout incubation. For both EIAs, intra-assay coefficients of variation were $>10 \%$. Inter-assay coefficients of variation at $30 \%$ and $70 \%$ binding were $12.8 \%$ and $13.2 \%$ for progestagens, and $11.6 \%$ and $13.5 \%$ for androgens. Assay sensitivities (calculated at $90 \%$ binding for each EIA) were 2.12 and $0.74 \mathrm{ng} / \mathrm{mL}$ for testosterone and progesterone EIAs, respectively. All extracts were measured in duplicate and after dilution with EIA buffer. Steroid levels are expressed as nanograms per gram of dried excreta.

\subsection{Statistical analysis}

For each individual parrot, urofecal steroid baselines were calculated using an iterative process in which values that exceeded 2 standard deviations (SD) above the mean were excluded (Pelican et al., 2005). The average was then recalculated and the elimination process repeated until no values exceeded 2SD above the mean. The average of the remaining values was considered as the "baseline" for that bird. Values greater than twice the baseline were defined by the authors as "peaks" for urofecal androgens and progestagens, respectively. The eight pairs were categorized into three groups: pairs with nestlings $(n=3)$; pairs with infertile eggs $(\mathrm{n}=2)$ and pairs without eggs $(\mathrm{n}=3)$. Additionally, to check whether urofecal progestagen measurements can be used as predictors of reproductive status, binary logistic regression was conducted to compare hormonal levels of samples from laying females during breeding (pre-laying and laying) and nonbreeding phases (IBM SPSS Statistics for Windows - Version 24, IBM Corporation, Armonk, NY). Pre-laying included two weeks prior to the onset of oviposition, while laying comprised the period between onset of oviposition and clutch completion. Results are expressed as odds ratio (OR) with 95\% confidence intervals (95\% $\mathrm{CI}$ ), and odds were converted to probability percentages (P) using the equation $\mathrm{P}=($ Odds $/ 1+$ Odds $) \times 100$ (Viera, 2008). Sensitivity (true positive rate) and specificity (true negative rate) of progestagen measurements were defined as the proportion of breeding and non-breeding samples, respectively, that were correctly identified as such. Accuracy was estimated as the proportion of true positive and true negative in all assayed samples. These analyses were not performed for urofecal androgens because repeated semen collections to attest testicular gametogenic activity would overstress males and, probably, impair breeding performance (i.e. males could not be properly classified according to their sperm production).

\section{Results}

Data regarding rainfall, temperature and photoperiod of the study area are summarized in Fig. 1. Average monthly photoperiod varied from 10.72 to $13.27 \mathrm{~h}$ of daylight, with the shortest and the longest photoperiod occurring in June and December, respectively. Minimum average temperature happened in June $\left(18.0^{\circ} \mathrm{C}\right)$, while maximum average temperature occurred in February $\left(25.5^{\circ} \mathrm{C}\right)$. Average monthly rainfall varied from 0.00 to $220.70 \mathrm{~mm}^{3}$, with no rainfall in July and maximum rainfall in January.

Despite only five individuals producing eggs between June 2011 and May 2012 (total of 7 egg-lay cycles), we observed courtship, copulation and nesting behaviors in all pairs. Egg laying occurred from August to October (late winter - mid-spring), and females laid a mean of $3.14 \pm 0.24$ eggs per clutch. Six out of twenty-two eggs hatched (all nestlings derived from pairs 01, 03 and 09), whereas pairs 05 and 06 laid eight and five infertile eggs, respectively (Figs. 2 and 3). The interval between consecutive eggs laid in a clutch averaged $3.60 \pm 0.51$ days (range: $1-8$ days), and eggs were naturally incubated for $25.86 \pm 0.55$ days (range: 24-28 days). Although eggs from pairs 05 and 06 were infertile, we did not remove the eggs from the nests in order to monitor nest abandonment behavior and its impact on hormonal profiles. Egg incubation in these pairs was extended to $43.75 \pm 3.06$ days (ranging from 35 to 50 days), and hence, both females laid a second clutch approximately two months apart (Fig. 3). No eggs or nestlings were recorded for pairs 02, 04 and 10 during this research (Fig. 4).

Urofecal androgen and progestagen profiles from breeding, laying and non-laying pairs are depicted in Figs. 2, 3 and 4, respectively. Regardless of the reproductive outcome all males exhibited androgen peaks during the copulation - egg laying period (July-October), but intriguingly five out of eight males displayed another series of rises soon after molting (from midFebruary to March). These increases had similar or higher amplitudes than those registered during breeding season, and they were not exclusive to reproductively successful males. On the other hand, urofecal progestagen peaks were only detected in females producing nestlings and infertile eggs, with non-laying females remaining at baseline levels throughout the entire study. As shown in Fig. 5, progestagen surges in 7 egg-lay cycles occurred invariably at the time of clutch formation between 7 days before and 5 days after onset of laying. Thereafter, urofecal progestagens dropped sharply to baseline levels where they continued until hatching or egg removal. In two cases, progestagen levels rose again within 1-2 days after hatching or nest abandonment (Fig. 5A and D, respectively).

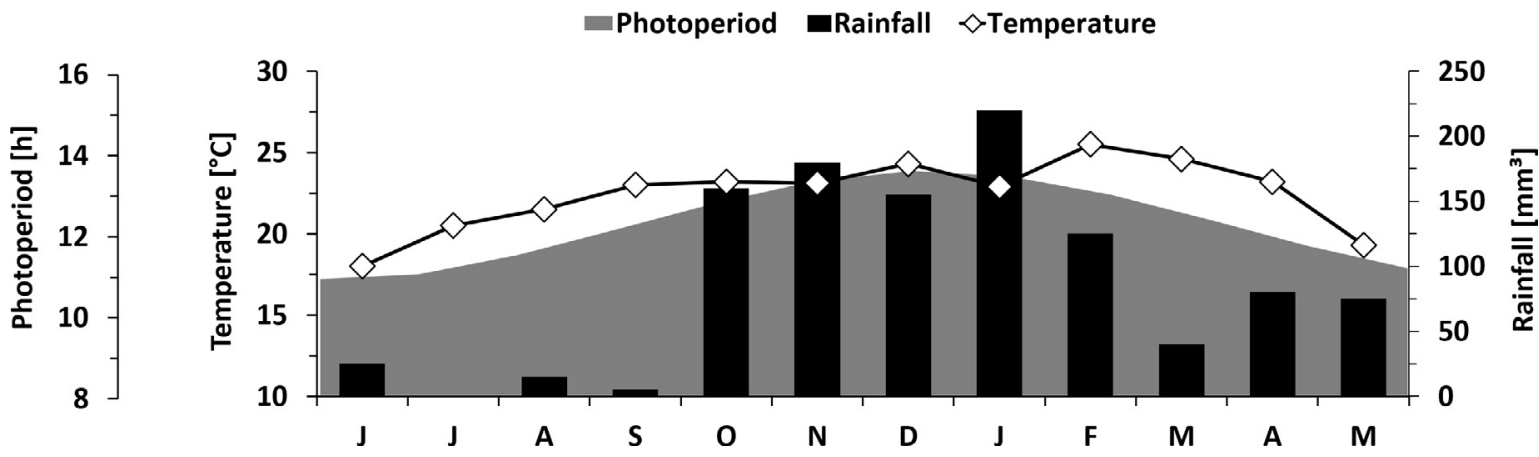

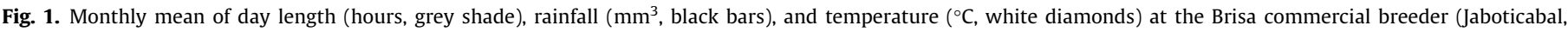
Brazil - 21으 latitude) from June 2011 to May 2012. 


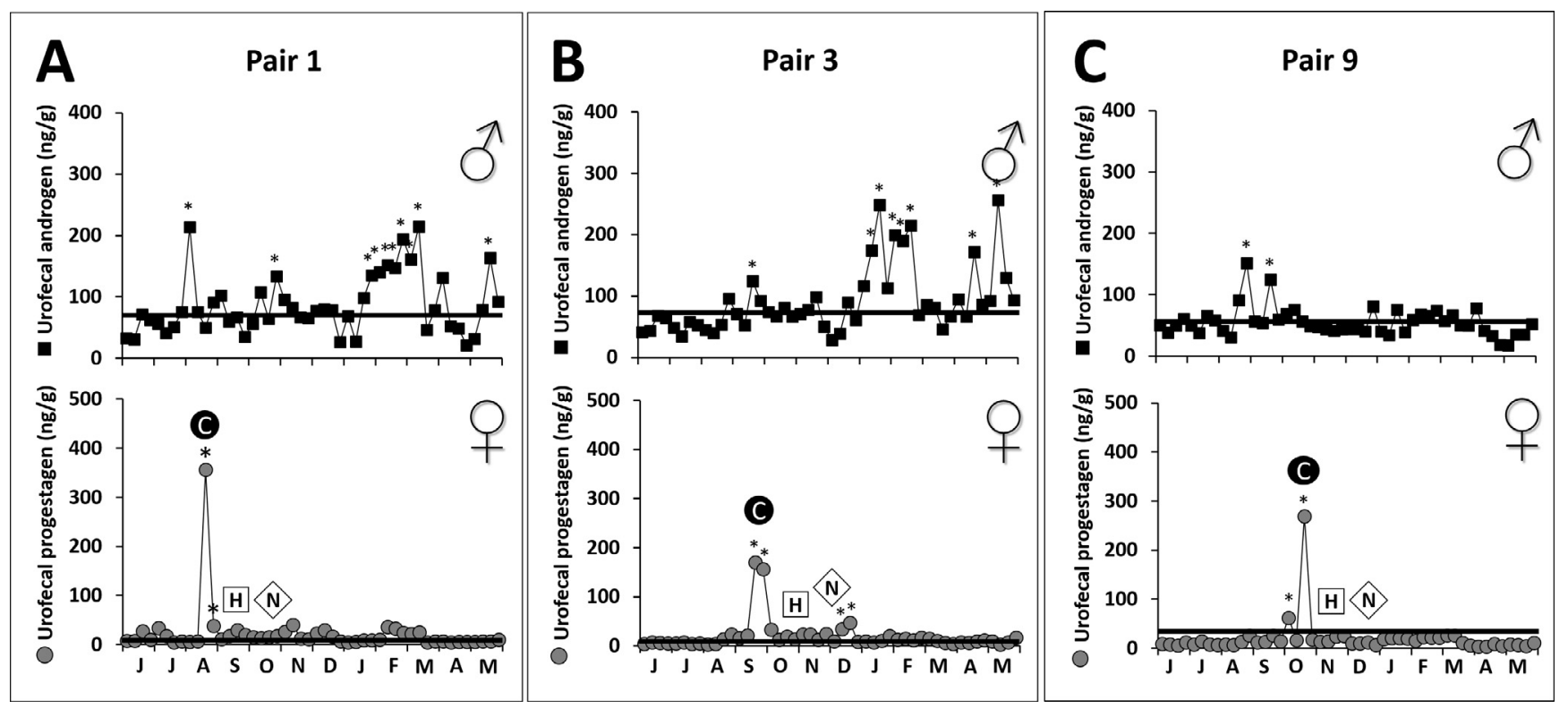

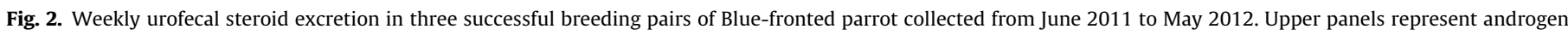

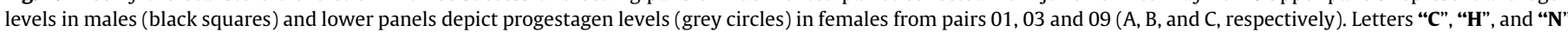

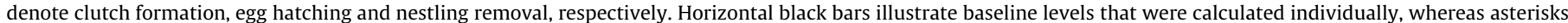
indicate steroid metabolite peaks (refer to Section 2 for more information regarding baseline and peak calculation).

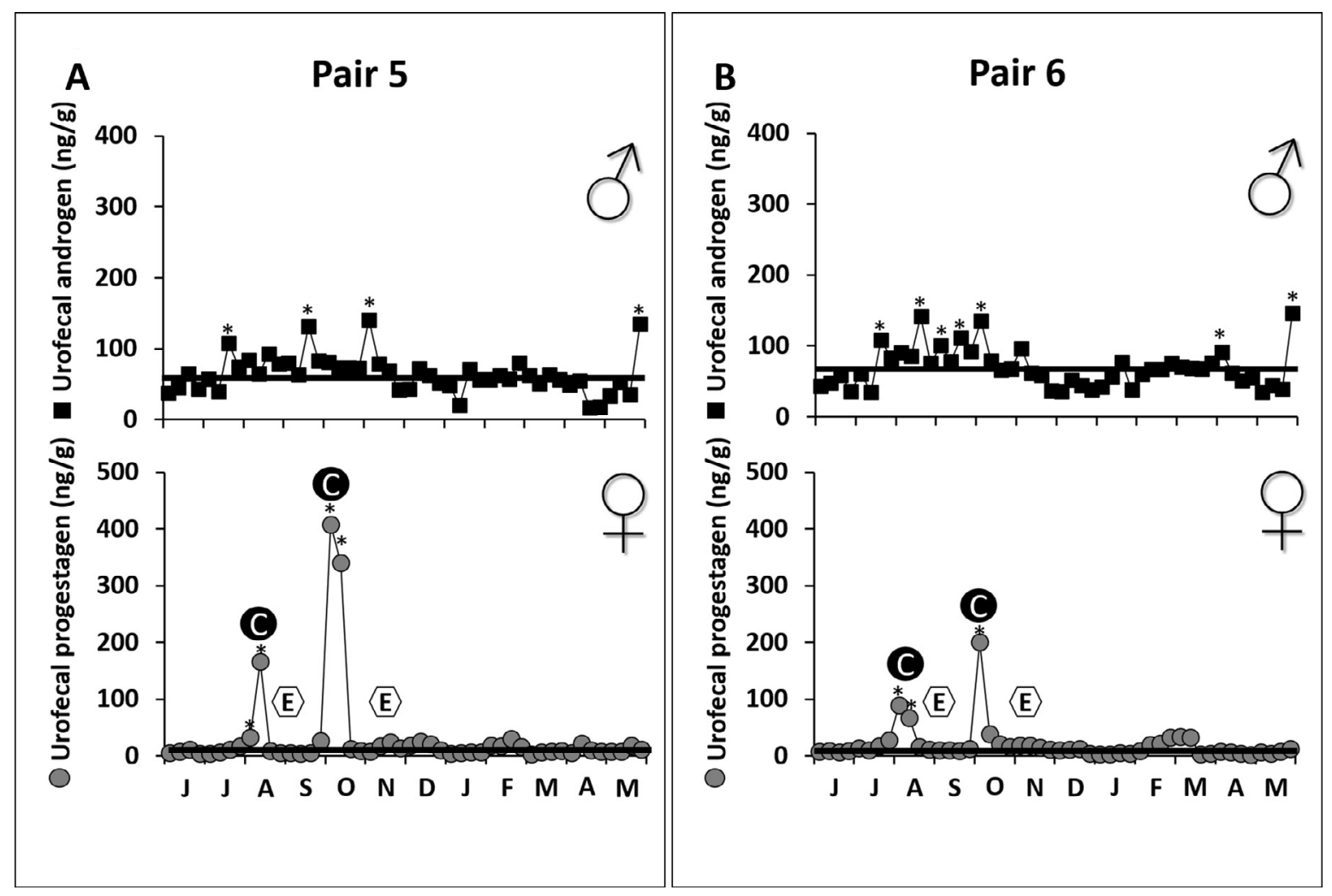

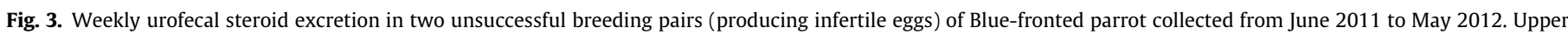

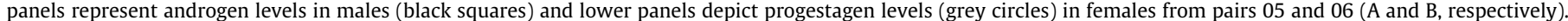

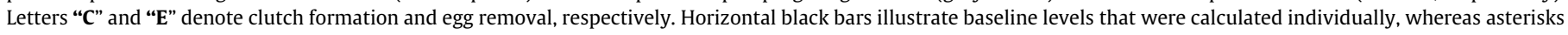
indicate steroid metabolite peaks (refer to Section 2 for more information regarding baseline and peak calculations).

A total of 205 samples were collected from laying females of which 162 and 43 were classified as non-breeding and breeding phases, respectively. These samples were then grouped according to their progestagen levels in order to check distribution of both phases (Fig. 6A). Samples from the breeding phase were scattered among all progestagen ranges, whereas all samples from the nonbreeding phase had levels lower than $40 \mathrm{ng} / \mathrm{g}$. Using logistic regression, we found a significant effect of urofecal progestagens 


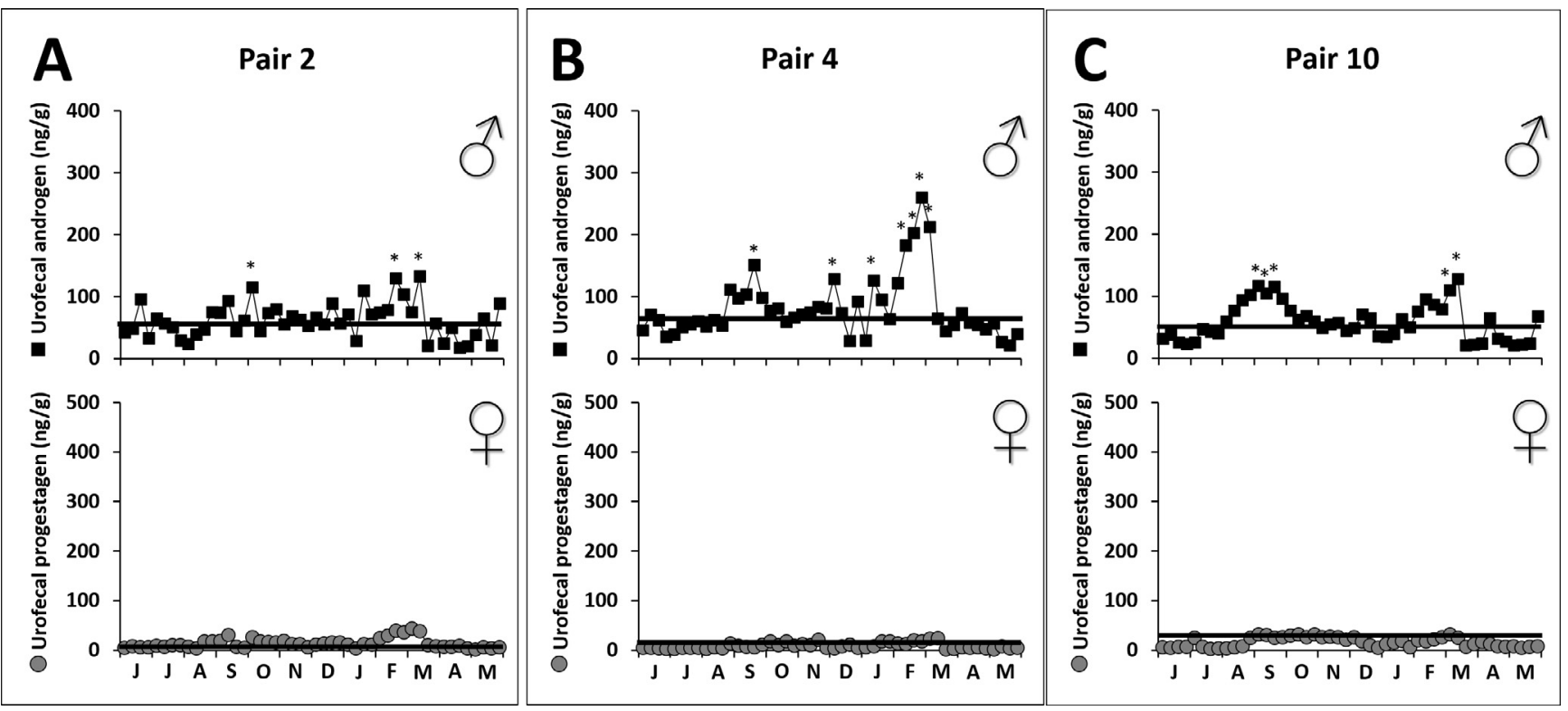

Fig. 4. Weekly urofecal steroid excretion in three unsuccessful breeding pairs (producing no eggs) of Blue-fronted parrot collected from June 2011 to May 2012 . Upper panels represent androgen levels in males (black squares) and lower panels depict progestagen levels (grey circles) in females from pairs 02,04 and 10 (A, B and C, respectively). Horizontal black bars illustrate baseline levels that were calculated individually, whereas asterisks indicate steroid metabolite peaks (refer to Section 2 for more information regarding baseline and peak calculations).

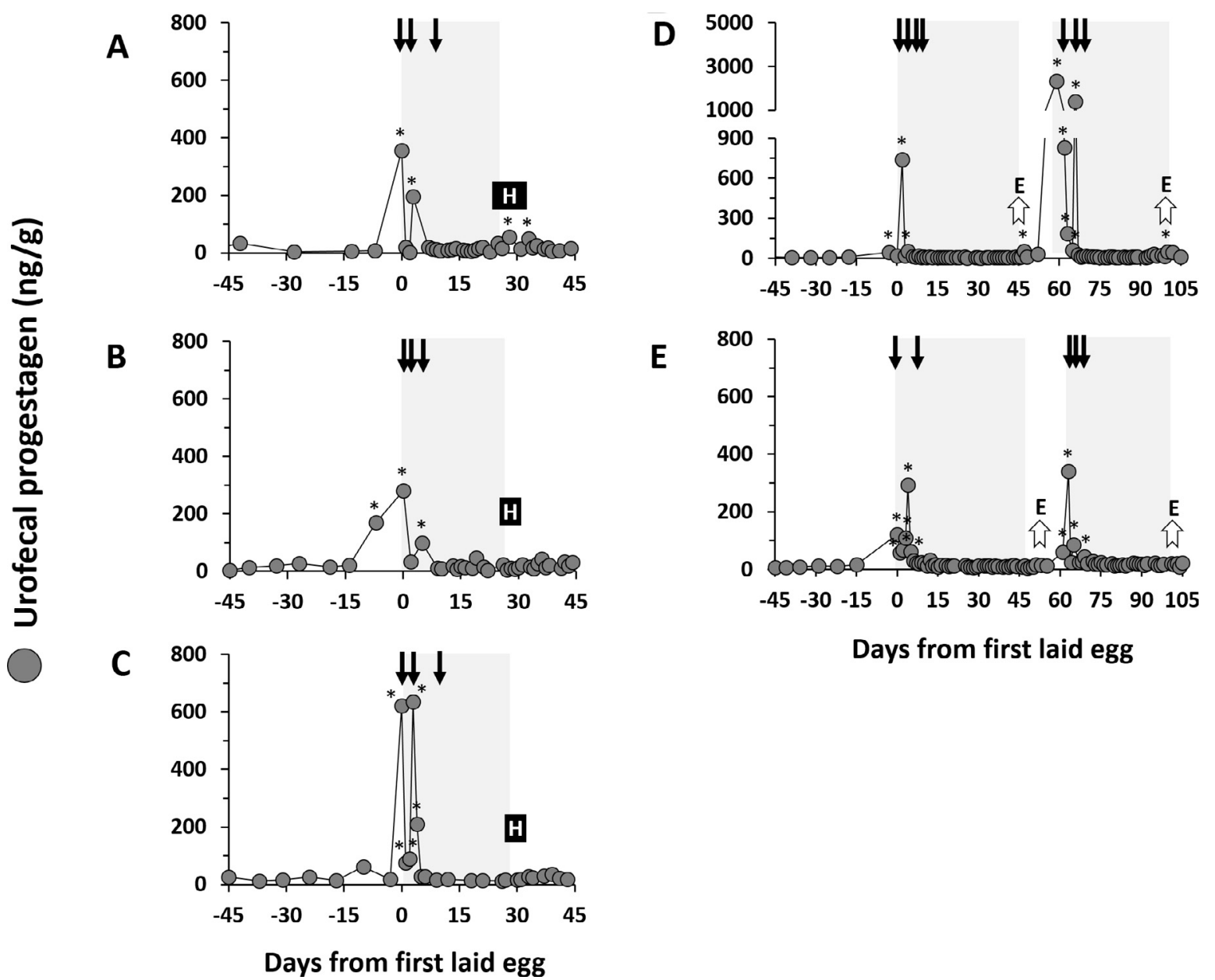

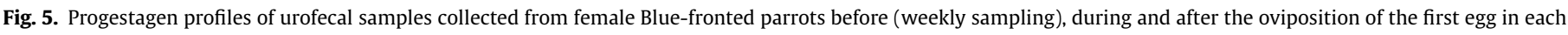

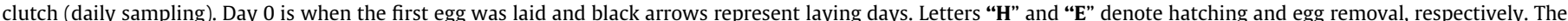

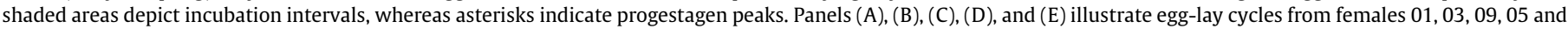
06 , respectively. 


\section{Non breeding $\square$ Breeding}
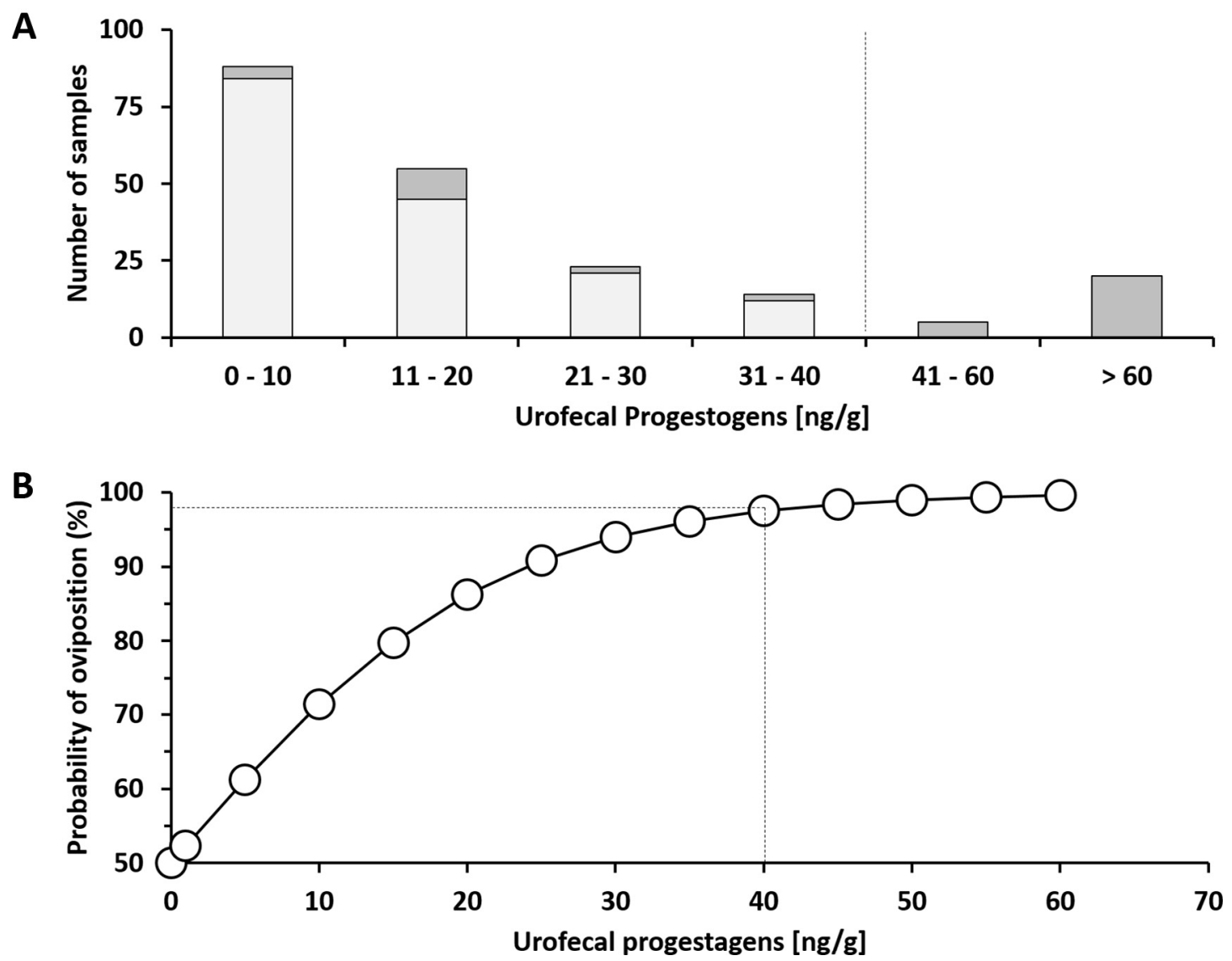

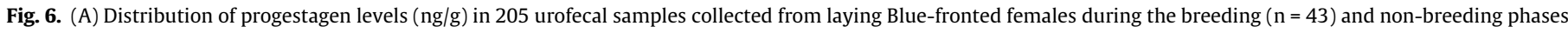

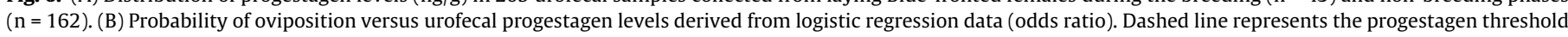

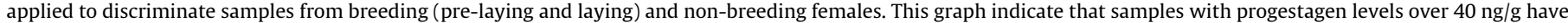
more than $97.5 \%$ probability to be from pre-laying or laying females.

on reproductive status (OR 1.096; 95\% CI 1.061-1.133; $\mathrm{P}=0.0001$ ), with breeding and non-breeding phases showing mean progestagen levels of $152.29 \pm 49.28$ and $13.22 \pm 0.71 \mathrm{ng} / \mathrm{g}$, respectively. Afterwards, OR was used to calculate probability of oviposition based onurofecal progestagen levels (Fig. 6B), and results indicated that samples with progestagen levels above $40 \mathrm{ng} / \mathrm{g}$ have more than $97.5 \%$ probability to be from females that will lay within 2 weeks or that are currently laying. When applying a threshold value of $41 \mathrm{ng} / \mathrm{g}$ for laying females, we noticed that our singlesample analysis erroneously categorized 18 breeding samples (41.86\%) as non-breeding (a majority of them occasionally declined in progestagen levels within laying period), whereas no samples were mistakenly diagnosed as breeding. Next, we used the same threshold for non-laying females and only one out of 144 samples (0.69\%) was considered a false positive. By lumping together samples from all females, this threshold provided sensitivity, specificity and accuracy of $58.13 \%, 99.67 \%$ and $94.55 \%$, respectively.

\section{Discussion}

The present data validate the measurement of urofecal androgen and progestagen metabolites to assess reproductive status in Blue-fronted parrots. Hormonal profiles of Blue-fronted pairs with different reproductive performances provided valuable insight into some of the issues that may lead to unsuccessful breeding. For example, laying females displayed urofecal progestagen peaks prior to and during clutch formation, whereas non-laying females remained at baseline levels all year round. This progestagen pat- tern in laying parrots was expected, considering the close relationship between progesterone and ovulation in several bird species (Bronneberg et al., 2007; Brown et al., 2016; Jensen and Durrant, 2006; Johnson, 2011; Rehder at al., 1986; Sockman and Schwabl, 1999). In contrast, flat progestagen profiles in non-laying parrots may indicate a lack of large ovarian hierarchical follicles, since granulosa cells from these follicles have been implicated as the primary source of progesterone in laying hens (Johnson, 2011). Similar findings have already been described for canvas back duck (Aythya valisineria; Bluhm et al., 1983), Japanase quail (Coturnix japonica; Gulati et al., 1981) and American kestrel (Falco sparverius; Rehder et al., 1986), with non-laying females exhibiting no progesterone peaks during pre-laying and laying stages. Another explanation refers to the presence of large ovarian follicles that did not ovulate, circumstances formerly documented in female ostriches using repeated transcutaneous ultrasound and analysis of plasma hormones (Struthio camelus; Bronneberg et al., 2007). This could explain why non-laying females displayed several reproductive behaviors (including copula) without oviposition. Unfortunately, ultrasound scanning was not performed in our current study because of technical and logistics difficulties and limitations in medium-sized parrots, and the stress-induced suppression of egg laying cycle caused by excessive handling (Breuner, 2011; Helmer, 2005; Hofbauer and Krautwald-Junghanns, 1999; McMillan, 1994; Wang et al., 2017). As we were unable to assess estrogen production in Blue-fronted females due to validation issues with the two EIAs tested in our laboratory, monitoring of developing follicles was not possible. 
Unlike progestagens, urofecal androgen profiles did not offer a clear discrimination between successful and unsuccessful male amazons as all individuals presented hormonal peaks during the breeding season. In addition, all males displayed a variety of reproductive behaviors such as nest activity, courtship and copulation, facts that to a certain extent corroborates our endocrine data, given that androgens play a key role in regulating sexual behaviors in male birds (Deviche et al., 2011; Fusani, 2008). The lack of significant differences in androgen levels between males of successful and unsuccessful pairs was previously reported in great hornbills (Buceros bicornis; Crofoot et al., 2003) and whooping cranes (Grus americana; Brown et al., 2016). According to Brown et al. (2016), this homogeneity may be related to the absence of mating competitors in captivity. Alternatively, it is possible that testes from unsuccessful amazons were steroidogenically and spermatogenically active, but reproduction was not achieved as a result of previous life experiences (e.g. animal abuse during illegal trade, social trauma in overcrowded aviaries, imprinting, etc.), recent pairing, pair inexperience or pair incompatibility. Nonetheless, the hypothesis is difficult to confirm without repeated semen collection to determine sperm production with the ultimate goal of classifying males according to their gametogenic activity. Another intriguing finding of our study is that, although reproductive activities were concentrated from August to October, five out of eight males demonstrated a number of androgen surges between late summer and early autumn. Androgen increases at the onset and during breeding season were not surprising, given that courtship and copulation coincides with the period of maximal testicular development in many bird species (Deviche et al., 2011). However, transient resumption of testosterone secretion after postnuptial molt have been also depicted in males of some species including house sparrow (Passer domesticus; Hegner and Wingfield, 1986), white stork (Ciconia ciconia; Hall et al., 1987), Peking duck (Anas platyrhynchos; Jallageas et al., 1978), common teal (Anas crecca; Jallageas et al., 1978) and Houbara bustard (Chlamydotis undulata; Saint Jalme et al., 1996). According to Hegner and Wingfield (1986), the gonadal recrudescence shortly after molt indicates that restoration of photosensitivity in house sparrows is feasible if day length is still long enough to stimulate gonadal function, and it seems to be associated with social competition for nesting sites and mates. Thus, we believe that the same principle may apply to male parrots since favorable environmental conditions (i.e. long days and high rainfall) were still prevailing at the time molt was completed. But whether or not these peaks of androgen in late summer-early autumn are followed by the recovery of spermatogenesis definitely merits further investigation.

As in other birds, reproductive behaviors and gonadal steroidogenesis in laying pairs of Blue-fronted amazon (and even in males from non-laying pairs) were initiated during periods of increasing day length. Thereafter, hormone secretion in egg-laying pairs decreased throughout egg incubation and chick rearing, and in those cases of infertile eggs both males and females displayed increased gonadal activity before and during the formation of a second clutch. Notwithstanding, five males and three laying females remained at baseline levels between late spring and early summer. Even though they had no eggs or nestlings at this time, they were still under stimulatory conditions and several weeks prior to molt (exceptions being pairs 03 and 09 which were still feeding their offspring). These findings are in a way consistent with the common knowledge among Brazilian breeders and zoos that copulation and egg laying in amazon parrots predominantly occur from July to October, and are rarely observed from November through January. This decline in reproductive activity and gonadal hormone production may reflect the onset of photorefractoriness in this species. Seasonal variations in the success rate of semen collection in birds of the genus Amazona have been recently described by Bublat et al. (2017), who achieved high success rates between late winter and mid-spring but very low to zero rates throughout the summer and autumn. Although such data apparently support our hypothesis, further studies involving neuro- and pituitary hormones or light schedules are required to draw more definitive conclusions about photorefractoriness in amazon parrots.

Finally, in an effort to ascertain whether progestagen metabolites can be used for predicting reproductive status in amazon females, we assessed the relationship between urofecal progestagen levels and probability of oviposition. Similar attempts using urinary and fecal steroids have been made in mammals to diagnose pregnancy and ovulation (Garrott et al., 1998; Kirkpatrick et al., 1992; Ostrowski et al., 2005; White et al., 1995). To our knowledge no research in birds demonstrated the ability of these noninvasive methods to discriminate between breeding and non-breeding phases. As a preliminary step, we have established that urofecal samples with progestagen levels over $40 \mathrm{ng} / \mathrm{g}$ have very high probability $(>97.5 \%)$ to be from pre-laying or laying females. The singlesample analysis yielded $94.55 \%$ accuracy in predicting breeding when a threshold of $41 \mathrm{ng} / \mathrm{g}$ was applied. This accuracy is within the range formerly cited for pregnancy diagnosis in mammalian species (55-100\%; Ostrowski et al., 2005). However, sensitivity of our measurements was considered poor $(58.13 \%)$ mostly because many intermittent falls in progestagen levels during the laying period were wrongly categorized as non-breeding samples. One way for minimizing this drawback is to examine more than one sample within a short period of time, a procedure previously recommended by White et al. (1995) to ensure pregnancy diagnosis in elk (Cervus elaphus nelsoni). It is important to emphasize that choosing a progestagen threshold for breeding discrimination in females parrots is a subjective decision that will depend on whether false negatives or false positives are more relevant to the objectives of a given study. Therefore, future studies should focus on testing this protocol (single vs. multiple samples) with a larger number of female amazons to refine our predictions for later use in artificial insemination and breeder selection.

In conclusion, annual profiles of urofecal steroids combined with reproductive data in Blue-fronted amazon pairs indicate that unsuccessful males retained a gonadal hormone production closer to successful ones, whereas ovarian function in non-laying females clearly differed from that in laying females. Our research also revealed a biphasic pattern of androgen excretion in most males with peaks closely correlated to breeding season (late wintermid spring), and additional rises occurring shortly after molt (late summer-early autumn). This endocrine configuration was not perceived in female parrots, which seemingly ceased ovarian activity in late spring-early summer. Furthermore, urofecal progestagen measurements enabled us to correctly discriminate the reproductive status in females with reasonable accuracy.

\section{Acknowledgments}

This research was funded by São Paulo Research Foundation (FAPESP Process N. 10/06500-7). Thanks to the Núcleo de Pesquisa e Conservação de Cervídeos (NUPECCE - FCAVJ - UNESP) for the permission to conduct part of our study in its laboratories, and for the staff assistance during hormonal analysis. Special gratitude goes to Dr. Marcílio Nichi for the statistical support. Many thanks go to Dr. Gloria I. Perez and Dr. Loro Lo-LajaKujjo for editorial review of the article.

\section{Appendix A. Supplementary data}

Supplementary data associated with this article can be found, in the online version, at https://doi.org/10.1016/j.ygcen.2018.02.006. 


\section{References}

BirdLife International, 2016. Amazona aestiva. The IUCN Red List of Threatened Species 2016:e.T22686332A93107322.http://dx.doi.org/10.2305/IUCN. UK.2016-3.RLTS.T22686332A93107322.en. Downloaded on 26 May 2017.

BirdLife International, 2017. The BirdLife checklist of the birds of the world: Version 9.1.http://www.birdlife.org/datazone/userfiles/file/Species/Taxonomy/BirdLife_ Checklist_Version_91.zip

Bluhm, C.K., Phillips, R.E., Burke, W.H., 1983. Serum levels of luteinizing hormone $(\mathrm{LH})$, prolactin, estradiol, and progesterone in laying and nonlaying canvas back ducks (Aythya valisineria). Gen. Comp. Endocrinol. 52, 1-16.

Breuner, C.W., 2011. Stress and reproduction in birds. In: Norris, D.O., Lopez, K.H. (Eds.), Hormones and Reproduction of Vertebrates - Volume 4: Birds. Academic Press, San Diego, USA, pp. 129-151.

Bronneberg, R.G.G., Taverne, M.A.M., Dileleman, S.J., Decuypere, E., Bruggeman, V., Vernooij, J.C.M., Stegemen, J.A., 2007. The relation between ultrasonographic observations in the oviduct and plasma progesterone, luteinizing hormone and estradiol during the egg laying cycle in ostriches. Domest. Anim. Endocrinol. 32, 15-28.

Brown, J., Walker, S., Steinman, K., 2004. Endocrine manual for the reproductive assessment of domestic and non-domestic species. Endocrine Research Laboratory, Department of Reproductive Sciences, Conservation and Research Center, National Zoological Park, Smithsonian Institution, Handbook, pp. 1-93.

Brown, M.E., Converse, S.J., Chandler, J.N., Shafer, C., Brown, J.L., Keefer, C.L., Songsasen, N., 2016. Female gonadal hormones and reproductive behaviors as key determinants of successful reproductive output of breeding whooping cranes (Grus americana). Gen. Comp. Endocr. 230, 158-165.

Bublat, A., Fischer, D., Bruslund, S., Schnieder, H., Meinecke-Tillmann, S., Wehrend, A., Lierz, M., 2017. Seasonal and genera-specific variations in semen availability and semen characteristics in large parrots. Theriogenology 91, 82-89.

Christofoletti, M.D., 2014. Reprodução de papagaio-verdadeiro (Amazona aestiva) em cativeiro: perfil anual de esteróides sexuais e ensaio de estímulo hormonal exógeno (Ph.D. Thesis). Universidade Estadual Paulista - Faculdade de Ciências Agrárias e Veterinárias de Jaboticabal, Jaboticabal, p. 72.

Costantini, V., Carraro, C., Bucci, F., Simontacchi, C., Lacalandra, G., Minoia, P., 2009. Influence of a new slow-release GnRH analogue implant on reproduction in the Budgerigar (Melopsittacus undulatus, Shaw 1805). Anim. Reprod. Sci. 111, 289301.

Crofoot, M., Mace, M., Azua, J., MacDonald, E., Ckezala, N.M., 2003. Reproductive assessment of the great hornbill (Buceros bicornis) by fecal hormone analysis. Zoo Biol. 22, 135-145.

Deviche, P., Hurley, L.L., Fokidis, H.B., 2011. Avian testicular structure, function ad regulation. In: Norris, D.O., Lopez, K.H. (Eds.), Hormones and Reproduction of Vertebrates - Volume 4: Birds. Academic Press, San Diego, USA, pp. 27-70.

Engebretson, M., 2006. The welfare and suitability of parrots as companion animals: a review. Anim. Welfare 15, 263-276.

FAO, 2011. International trade in wild birds, and related bird movements, in Latin America and the Caribbean. Animal Production and Health Paper No. 166. Rome.

Fusani, L., 2008. Testosterone control of male courtship in birds. Horm. Behav. 54, $227-233$.

Garrott, R.A., Monfort, S.L., White, P.J., Mashburn, K.L., Cook, J.G., 1998. One-sample pregnancy diagnosis in elk using fecal steroid metabolites. J. Wildl. Dis. 34, 126131.

Graham, L., Schwarzenberger, F., Möstl, E., Galama, W., Savage, A., 2001. A versatile enzyme immunoassay for the determination of progestogens in feces and serum. Zoo Biol. 20, 227-236.

Gulati, D.P., Nakamura, T., Tanabe, Y., 1981. Diurnal variations in plasma LH, progesterone, testosterone, estradiol, and estrone in the Japanese quail. Poult. Sci. 60, 668-671.

Hahn, A., Reitemeier, S., Gottschalk, J., Haense, M., Schmidt, V., Steinbach-Sobiraj, K., Krautwald-Junghanns, M.-E., Einspanier, A., 2011. Endocrinologic studies of male psittacine birds for the evaluation of their reproductive status. Tierarztl Prax Ausg K Kleintiereheimtiere 39, 249-257.

Hall, M.R., Gwinner, E., Bloesh, M., 1987. Annual cycles in moult, body mass, luteinizing hormone, prolactin and gonadal steroids during the development and sexual maturity in the white stork. J. Zool. Lond. 211, 467-486.

Hegner, R.E., Wingfield, J.C., 1986. Gonadal development during autumn and winter in house sparrows. Condor 88, 269-278.

Helmer, P., 2005. Diagnostic imaging. In: Harrison, G.J., Lightfoot, T. (Eds.), Clinical Avian Medicine -. Spix Publising, Palm Beach USA, pp. 653-659.

Hofbauer, H., Krautwald-Junghanns, M.E., 1999. Transcutaneous ultrasonography of the avian urogenital tract. Vet. Radiol. Ultrasound 40, 58-64.

IUCN, 2014. The IUCN Red list of threatened species. Version 2014.2. http://www. iucnredlist.org
Jallageas, M., Tamisier, A., Assenmacher, I., 1978. A comparative study of the annual cycles in sexual and thyroid function in male Peking ducks (Anas platyrhynchos) and teal (Anas crecca). Gen. Comp. Endocr. 36, 201-210.

Jensen, T., Durrant, B., 2006. Assessment of reproductive status and ovulation in female brown kiwi (Apteryx mantelli) using fecal steroids and ovarian follicle size. Zoo Biol. 25, 25-34.

Johnson, A.L., 2011. Organization and functional dynamics of the avian ovary. In: Norris, D.O., Lopez, K.H. (Eds.), Hormones and Reproduction of Vertebrates Volume 4: Birds. Academic Press, San Diego, USA, pp. 71-90.

Kirkpatrick, J.F., Bancroft, K., Kincy, V., 1992. Pregnancy and ovulation detection in bison (Bison bison) assessed by means of urinary and fecal steroids. J. Wildl. Dis. 28, 590-597.

Lee, J., Tell, L., Lasley, B., 1999. A comparison of sex steroid hormone excretion and metabolism by psittacine species. Zoo Biol. 18, 247-260.

Lovas, E.M., Johnston, S.D., Filippich, L.J., 2010. Using a GnRH agonist to obtain an index of testosterone secretory capacity in the cockatiel (Nymphicus hollandicus) and sulphur-crested cockatoo (Cacatua galerita). Aust. Vet. J. 88, 52-56.

McMillan, M.C., 1994. Imaging techniques. In: Ritchie, B.W., Harrison, G.J., Harrison, L.R. (eds.), Avian Medicine - Principles and Application, Lake Worth, USA, pp. 246-326.

Myers, S.A., Millam, J.R., el Halawani, M.E., 1989. Plasma LH and prolactin levels during the reproductive cycle of the cockatiel (Nymphicus hollandicus). Gen. Comp. Endocrinol. 73, 85-91.

Olah, G., Butchart, S.H.M., Symes, A., Guzmán, I.M., Cunningham, R., Brightsmith, D. J., Heinsohn, R., 2016. Ecological and socio-economic factors affecting extinction risk of parrots. Biodivers. Conserv. 25, 205-223.

Ostrowski, S., Blanvillain, C., Mésochina, P., Ismail, K., Schwarzenberger, F., 2005 Monitoring reproductive steroids in feces of Arabian oryx: toward a noninvasive method to predict reproductive status in the wild. Wildl. Soc. Bull. 33, 965-973.

Pelican, K., Brown, J., Wildt, D., Ottinger, M., Howard, J., 2005. Short term suppression of follicular recruitment and spontaneous ovulation in the cat using levonorgestrel versus a GnRH antagonist. Gen. Comp. Endocr. 144, 110 121.

Pereira, R.J.G., Granzinolli, M.A.M., Duarte, J.M.B., 2010. Annual profile of fecal androgen and glucocorticoid levels in free-living male American kestrels from southern mid-latitude areas. Gen. Comp. Endocr. 166, 94-103.

Piacentini, V.Q., Aleixo, A., Agne, C.E., Maurício, G.N., Pacheco, J.F., Bravo, G.A., Brito, G.R.R., Naka, L.N., Olmos, F., Posso, S., Silveira, L.F., Betini, G.S., Carrano, E., Franz, I., Lees, A.C. Lima, L.M., Pioli, D., Schunck, F. Amaral, F.R., Bencke, G.A., CohnHaft, M., Figueiredo, L.F.A., Straube, F.C., Cesari, E., 2015. Annotated checklist of the birds of Brazil by the Brazilian Ornithological Records Committee. Braz. J. Ornithol. 23, 91-298.

Rehder, N., Bird, D., Lague, P., 1986. Variations in plasma corticosterone, estrone estradiol-17 $\beta$, and progesterone concentrations with forced renesting, molt, and body weight of captive female American kestrels. Gen. Comp. Endocr. 62, 386393.

Riters, L.V., Alger, S.J., 2011. Hormonal regulation of avian courtship and mating behaviors. In: Norris, D.O., Lopez, K.H. (Eds.), Hormones and Reproduction of Vertebrates - Birds Volume 4. Academic Press, San Diego, USA, pp. 153-180.

Saint Jalme, M., Williams, J., Mickaelian, I., Paillat, P., 1996. Seasonal variation of LH, sex steroids, body mass, molt and laying in two subspecies of Houbara Bustard, Chlamydotis undulata macqueenii and Chlamydotis undulata undulate housed in outdoor cages under natural conditions. Gen. Comp. Endocr. 102, $102-112$.

Seixas, G.H.F., Mourão, G., Galetti, M., Pizo, M.A., 2002. Biologia reprodutiva do papagaio-verdadeiro (Amazona aestiva) no Pantanal sul-mato-grossense, Brasil In: Galetti, M., Pizo, M.A. (Eds.), Ecologia e Conservação de Psitacídeos no Brasil Belo Horizonte. Melopsittacus Publicações Científicas, pp. 157-171.

Seixas, G.H.F., 2007. Projeto Papagaio-verdadeiro (Amazona aestiva): Manejo econservação no Pantanal e Cerrado de Mato Grosso do Sul, Brasil. PUBVET 1 410-412.

Sick, H., 2001. Ornitologia brasileira. Editora Nova Fronteira, Rio de Janeiro.

Sockman, K.W., Schwabl, H., 1999. Daily estradiol and progesterone levels relative to laying and onset of incubation in canaries. Gen. Comp. Endocr. 114, 257-268.

Viera, A.J., 2008. Odds ratios and risk ratios: what's the difference and why does it matter? South. Med. J. 101, 730-734.

Wang, X.J., Liu, L., Zhao, J.P., Jiao, H.C., Lin, H., 2017. Stress impairs the reproduction of laying hens: an involvement of energy. Worlds Poult. Sci. J. 73, 1-11.

Weston, M.K., Memon, M.A., 2009. The illegal parrot trade in Latin America and its consequences to parrot nutrition, health and conservation. Bird Popul. 9, 76-83.

White, P.J., Garrott, R.A., Kirkpatrick, J.F., Berkeley, E.V., 1995. Diagnosing pregnancy in free-ranging elk using fecal steroid metabolites. J. Wildl. Dis. 31, 514-522. 